\title{
Parents' perceptions of food intolerance among under-five children in Gianyar Bali
}

\author{
Endy P Prawirohartono, MD, MPH; Ni Made Yuni Gumala, MD
}

\begin{abstract}
Objective To estimate the proportion of food intolerance in children based on parents' perception and to analyze factors associated with food elimination.

Methods A cross-sectional study was done among 250 mothers of under-five children in Gianyar District, Bali. Mothers were interviewed with a questionnaire concerning basic characteristics of the children, the family, a list of allergic diseases, disturbance after ingesting certain foods, food avoidance, the reason for eliminating certain foods, the person who gave advice, and probable parental history of allergic diseases.

Results Fifty-three children (21.2\%) were suspected to have 'probable allergic diseases' and six (2.4\%) had 'probable food intolerance'. Food elimination was practiced in $27(10.8 \%)$ families. 'Probable allergic parents' was found in $49(19.6 \%)$ families. There was a significant difference in child allergy in proportion to parental allergy $\left(x^{2}\right.$ test $\left.p<0.0001\right)$. Food elimination was not associated with parental allergies, children's allergies or children's ages $\left(x^{2}\right.$ test $p=0.36,0.47$, and 0.56 ), but seemed to be related to low educational status of mothers $\left(x^{2}\right.$ test $\left.p<0.0001\right)$ and fathers (Fisher's exact tests $p<0.0001$ ).

Conclusions The proportion of children with 'probable allergic diseases' was higher in families with 'probable allergic parents'. The proportion of food elimination was greater than the prevalence of 'probable food intolerance'. Low educational status of parents played an important role in this discrepancy of food elimination in children [Paediatr Indones 2003;43:226-229].
\end{abstract}

Keywords: parents' perceptions, food intolerance, food elimination

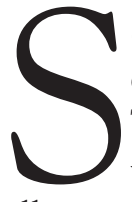

ome children develop an adverse reaction to certain foods with a wide variety of symptoms. The terms used to describe these symptoms were food sensitivity, food intolerance, food allergy, food aversions, and so on. Unfortunately parents and health professionals use the terms food sensitivity and food allergy interchangeably. ${ }^{1}$ The actual diagnosis is determined using double blind placebo controlled food challenge and other procedures such as intradermal skin test, radioallergosorbent test, basophil histamine release, intestinal mast cell histamine release, and intragastric provocation under endoscopy. ${ }^{2}$ These procedures are usually performed in a clinical research, and this diagnostic difficulties might limit the prevalence of this problem in a community study. Some studies showed the benefit of parents' perceptions of food intolerance to assess the prevalence of this problem in the community and thus can help the planning of health education for the community and health professionals. ${ }^{3,4}$

Balinese are mainly Hindus with special culture and food habits and may show a different perception concerning food intolerance among children. The aim of this study was to determine the prevalence of food intolerance among under-five children in Gianyar Bali based on parents' perception.

From the Department of Child Health, Division of Pediatric Nutrition, Medical School, Gadjah Mada University, Yogyakarta (EPP) and Dietitian Academy Denpasar, Bali (NMYG).

Reprint requests to: Endy P Prawirohartono, MD, MPH, Division of Pediatric Nutrition, Department of Child Health, Medical School, Gadjah Mada University, Yogyakarta, Indonesia. Tel. 62-274-561616, Fax. 62 274-583745, Email: endy_paryanto@pediatric-gmu.org

This manuscript was presented at The $12^{\text {th }}$ National Congress of Child Health and The $11^{\text {th }}$ ASEAN Pediatric Federation Conference in Bali, Indonesia, June 30 - July 4, 2002 


\section{Methods}

We performed a cross sectional study in Gianyar Sub District, Gianyar District, Bali from August to November 2001. Subjects were mothers and their under-five year-old children who agreed to be involved in this study. Trained interviewers collected data with a questionnaire. We purposely chose working mothers and housewives as subjects with almost equivalent proportions. Minimal sample size was 239 mothers based on the anticipated population proportion of food intolerance $(0.10)$ and a precision of 0.05 .6

The questionnaire consisted of basic characteristics of the subject and the family, a list of symptoms of allergic illnesses such as asthmatic attacks, wheezing, urticaria, etc., a list of questions concerning disturbance after ingesting certain foods, food avoidance, reasons for practicing food eliminations, person who gave advice for food elimination, and parental illnesses related to food intolerance such as asthma, urticaria, runny nose.
A child was defined as having 'probable food intolerance' when the mother reported a disturbance after ingesting certain food. Probable allergic diseases were defined as all of probable allergic diseases except 'probable food intolerance', therefore, according to parents, 'probable allergic diseases' did not relate to ingesting certain food.

Data were analyzed with $\mathrm{x}^{2}$-test or Fisher's exact test using SPSS 10.0 for Windows, and the $p$ value of less than 0.05 was defined as a significant difference.

\section{Results}

\section{Basic characteristics of the subjects}

The mothers were mostly housewives (66.0\%), highly educated $(64.4 \%)$; their husbands were private employees (32.0\%) and also highly educated (83.2\%). Most of the families had one or two children $(41.6 \%$

Table 1. Basic Characteristics of the subjects

\begin{tabular}{lrr}
\hline Characteristics & $\mathbf{n}$ & $\%$ \\
\hline Child's age & 58 & 23.2 \\
$0-11$ months & 143 & 57.2 \\
$12-35$ months & 49 & 19.6 \\
$36-60$ months & & \\
Father's occupation & 80 & 32.0 \\
Private employee & 79 & 31.6 \\
Labor & 51 & 20.4 \\
Civil servant & 27 & 10.8 \\
Merchant & 13 & 5.2 \\
Others & & \\
Mother's occupation & 165 & 66.0 \\
Housewife & 81 & 32.4 \\
Civil servant & 3 & 1.6 \\
Others & & \\
Education level of father & 16 & 6.4 \\
Primary school & 26 & 10.4 \\
Junior high school & 158 & 63.2 \\
Senior high school & 50 & 20.0 \\
University & & \\
Education of mother & 33 & 13.2 \\
Primary school & 56 & 22.4 \\
Junior high school & 121 & 48.4 \\
Senior high school & 40 & 16.0 \\
University & & \\
Number of children in the family & 104 & 41.6 \\
1 & 104 & 41.6 \\
2 & 34 & 13.6 \\
3 & 6.4 \\
4 & 1 & 0.4 \\
5 & 1 & 0.4 \\
\hline & &
\end{tabular}


and $41.6 \%$ respectively). There were 143 (57.2\%) children aged 12 - 35 months (Table 1 ).

\section{Probable allergic diseases}

Fifty-five $(21.2 \%)$ children suffered from 'probable allergic diseases', mostly runny nose (46 children). Other symptoms were morning cough (11 children), night cough (9 children), diarrhea (8 children), asthma ( 6 children), wheezing ( 5 children), vomiting (5 children), urticaria (4 children), day cough (2 children), and eczema (2 children).

\section{Probable food intolerance}

Only 6 children were diagnosed with 'probable food intolerance'. Candy, ice, and 'Chiki' snacks were most frequently reported as the cause followed by jackfruit (one child) and tea (one child).

\section{Food elimination}

Although we only found six (2.4\%) children suffering from 'probable food intolerance', there were 27 $(10.8 \%)$ parents who practiced food elimination which shows a large discrepancy between these two conditions. Egg was avoided by 20 children, crab by seven, and shrimp by six. Next was peanut (3 children), 'Chiki' snack and lamb (2 children), green bean, potatoes, wheat, chicken, "taro" snack, cheese, chocolate, and milk (one child each).

Of the 27 parents, only one gave unrelated reason for food elimination (dental caries), the others (23 parents) as allergic prevention. Two parents related food elimination to prevent cough and one to itching. Only three cases were recommended by doctors or paramedics, compared to 24 who decided for themselves.

\section{Probable allergic parents}

Forty nine (19.6\%) parents suffered from 'probable allergic diseases', 36 (14.4\%) had rhinitis allergica, 15 (6.0\%) urticaria, and $5(2.0 \%)$ asthma and it was possible that they had more than one illness. Most allergic children came from families with parental allergic diseases (Table 2).

\section{Relationships between food eliminations and related factors}

The practice of food eliminations may be influenced by factors such as parental allergies, child allergies,

TAble 2. The PROportion of ALLERGic CHILDREN AND ALLERGIC PARENTS

\begin{tabular}{llll}
\hline & Allergic parents $(+)$ & Allergic parents $(-)$ & p \\
\hline Allergic children $(+)$ & 25 & 28 & $<0.0001^{*}$ \\
Allergic children (-) & 24 & 173 & \\
\hline${ }^{*} \mathrm{x}^{2}$ test significantly difference & & &
\end{tabular}

Table 3. Food eliminations and Related factors

\begin{tabular}{llll}
\hline Factors & Food elimination (+) & Food elimination (-) & p value \\
\hline $\begin{array}{c}\text { Parental allergic illnesses } \\
\text { Yes }\end{array}$ & $4(8 \%)$ & $45(92 \%)$ & $0.36^{@}$ \\
No & $23(11.4 \%)$ & $178(88.6 \%)$ & \\
$\begin{array}{c}\text { Children allergic illnesses } \\
\text { Yes }\end{array}$ & $5(9 \%)$ & $48(91 \%)$ & $0.47^{@}$ \\
No & $22(11.2 \%)$ & $175(88.8 \%)$ & \\
$\begin{array}{l}\text { Children age } \\
<1 \text { year }\end{array}$ & $6(10 \%)$ & $52(90 \%)$ & $0.56^{@}$ \\
$\quad \geq 1$ year & $21(10.9 \%)$ & $171(89.1 \%)$ & \\
Education status of mother & $9(6 \%)$ & $152(94 \%)$ & $<0.0001^{*} @$ \\
$\quad$ High & $18(20.2 \%)$ & $71(79.8 \%)$ & \\
Low & $15(7 \%)$ & $193(93 \%)$ & $<0.0001^{* \#}$ \\
Education status of father & $12(29 \%)$ & $30(71 \%)$ & \\
High & & & \\
Low & & & \\
\hline
\end{tabular}

* significantly different

${ }^{\circledR} \mathrm{x}^{2}$ test, "Fisher exact test 
children's ages, and the education level of parents. Table 3 shows that low education of mothers and fathers significantly correlated with food eliminations.

\section{Discussion}

This study showed that from observation through parents' perceptions, the prevalence of food intolerance was $2.4 \%$. This was similar with reports of the prevalence of food allergy in children as $1.4 \%(0.5 \%$ to $3.8 \%)$ in the general population, ${ }^{6} 3.8 \%$ in the Netherlands, ${ }^{4}$ and $3 \%$ in England and Scotland. ${ }^{3}$ In this study, 'probable allergic illnesses' were found among $21.2 \%$ children. The causative agents reported were different from other countries due to different feeding habits and the amount of food consumed. The greater frequency of intolerance to soy in Japan, to peanuts in the United States, and to fish in Scandinavia may be associated with the relative amounts of these foods consumed in respective countries. ${ }^{7}$ In this study, egg was the predominant causative agent reported by parents. Sampson et al (1985) reported that egg accounted for 42\% of the hypersensitivity-induced reactions in 63 children with atopic dermatitis who experienced positive doubleblind placebo-controlled oral food challenges. ${ }^{8}$ Moreover, a study done in Sardjito Hospital by Elberink et al (1995) showed that of nine patients with 2-week positive challenge tests, egg allergy was found among six (77\%) patients. ${ }^{9}$

Parents usually worry about the negative impact of food intolerance to their children's health and practice food eliminations to prevent it. This study showed a discrepancy between food eliminations and 'probable food intolerance'. We found $10.8 \%$ parents imposed food eliminations compared to $2.4 \%$ parents who reported actual 'probable food intolerance'. The possible explanation was to prevent 'probable allergic diseases'. These were reported by $21.2 \%$ parents. From 53 children who suffered from 'probable allergic illnesses', $9 \%$ came from families who practice food elimination compared to $11 \%$ who did not practice food elimination but this difference was not statistically significant. Apparently, the decision was not based on the child's situation. In this study, low educated parents practiced more food elimination compared to those who were highly educated. Health personnel should be aware of this problem. In this study only $1.6 \%$ of parents practiced food elimina- tion based on doctor/paramedic advice. Rona \& Chinn (1987) reported that $67 \%$ of their cases were consulted to doctors. Furthermore they reported that the pattern of avoided food was very similar in children who received advice from health personnel and the children who were not adviced. ${ }^{3}$ Inappropriate food elimination could result in a serious problem for malnourished children since the food eliminated from their diet are usually animal proteins, especially eggs.

As a conclusion we reported that the proportion of children with 'probable allergic illnesses' was higher in families with 'probable allergic parents', the proportion of food elimination was greater than the prevalence of 'probable food intolerance' and low education of parents was related to this discrepancy of food elimination in children.

\section{References}

1. Ferguson A. Definitions and diagnosis of food intolerance and food allergy: consensus and controversy. J Pediatr 1992;121:S7-11.

2. Burks AW, Sampson HA. Diagnostic approaches to the patient with suspected food allergies. J Pediatr 1992;121:S64-71.

3. Rona RJ, Chinn S. Parents' perceptions of food intolerance in primary school children. Br Med J 1987;294:863-6.

4. Aardoom HA, Hirasing RA, Rona RJ, Sanavro FL, van den Heuvel EW, Leeuwenburg J. Food intolerance (food hypersensitivity) and chronic complaints in children: the parents' perception. Eur J Pediatr 1997;156:110-2.

5. Prawirohartono EP. Perceptions of mothers about food allergy. A preliminary report. Paediatr Indones 2001;41:180-184

6. Chandra RK, Gill B, Kumari S. Food allergy and atopic disease: pathogenesis, diagnosis, prediction of high risk, and prevention. Ann Allergy 1993;71:495-502.

7. Esteban MM. Adverse food reactions in childhood: concept, importance, and present problems. J Pediatr 1992;121:S1-3.

8. Sampson HA, McCaskill CC. Food hypersensitivity and atopic dermatitis: evaluation of 113 patients. J Pediatr 1985;107:669-75.

9. Elberink R, Hennepe I, Prawirohartono EP, Douwes AC. Food allergy in Indonesian children [Thesis]. Amsterdam: Free Univ.; 1995. 